\title{
Insights Into Instructors' Verbal Aggressiveness and Students' Machiavellianism Through Leadership Style and Motivational Climate
}

\author{
Alexandra Bekiari, PhD \\ Faculty of Physical Education and Sports Science, \\ University of Thessaly, Greece
}

doi: 10.19044/esj.2016.v12n25p90 URL:http://dx.doi.org/10.19044/esj.2016.v12n25p90

\begin{abstract}
The aim of the present study was threefold: a) to explore the relationship between perceived instructor verbal aggressiveness, leadership style, motivational climate and student Machiavellianism, b) to investigate the influence of instructor verbal aggressiveness on their leadership style, motivational climate and student Machiavellianism in physical education context and c) to propose students' and instructors' typology. The sample consisted of 247 Greek students (128 males, 119 females) aged 14-17 years old $(M=15.4, S D=.49)$ from secondary schools who completed four types of questionnaires during physical education classes. The results supported the internal consistency of the instruments. Statistically significant differences were observed in instructors' verbal aggressiveness, autocratic leadership teaching style, democratic leadership style and students' Machiavellianism between the two genders of the students. Perceived instructors' verbal aggressiveness was negatively related to their democratic teaching style and mastery climate. Also, there was a positive significant relationship between instructors' verbal aggressiveness and autocratic teaching style, performance climate and students' Machiavellianism. The results of regression analysis revealed that perceived instructors' verbal aggressiveness could significantly predict the variables of leadership teaching style, motivational climate and students' Machiavellianism. Distinct types of relations between students and instructors may be distinguished: the "insurrection", the "acceptance of authoritarianism" and the "effective democracy". The findings and the effects of the instructors' verbal aggressiveness on leadership style, motivational climate and students' Machiavellianism are further discussed and future research issues are suggested.
\end{abstract}

Keywords: Verbal aggressiveness; Machiavellianism; leadership style; motivation climate 


\section{Introduction}

\section{Verbal aggressiveness}

Communicating may sometimes take place aggressively. Verbal aggressiveness could be perceived as attacking on the self-concept of an individual rather than as attacking the position of a person. Such an attack on the self-concept can aim at inflicting psychological pain, such as humiliating, embarrassing or similarly painful feelings which may sometimes lead up to physical attacks (Infante \& Rancer, 1996; Infante \& Wigley, 1986; Rancer \& Avtgis, 2014). There were identified nine types of verbally aggressive messages used by instructors: competence attacks, work ethic attacks, swearing, threats, character attacks, nonverbal behaviors, teasing, background attacks, and physical appearance attacks (Myers, Brann \& Martin, 2013). It has been supported that teachers' verbal aggressiveness is negatively correlated with students' attendance and participation in the learning process (Myers, Edwards, Wahl, \& Martin, 2007; Samar \& Amiri, 2012), state motivation (Bekiari, Kokaridas \& Sakellariou, 2005; 2006; Manoli \& Bekiari, 2015; Myers, 2002; Teven, 2007; Teven \& McCroskey, 1997; Thweatt \& McCroskey, 1998), student-teacher communication (Bekiari \& Hasanagas, 2015; 2016; Bekiari \& Manoli, 2016; Bekiari \& Sakellariou, 2002; Hasanagas \& Bekiari, 2015; Myers et al., 2007; Rocca \& McCroskey, 1999) and classroom climate (Bekiari \& Syrmpas, 2015; Myers \& Rocca, 2000). Certain studies have provided information about physical education instructors' verbal aggression during lessons. It has been argued that physical education instructors' verbal aggressiveness is negatively correlated with students' learning process (Bekiari, Kokaridas \& Sakellariou, 2005), affective learning (Bekiari, 2012), prosocial fair-play behaviors (Hassandra, Bekiari, \& Sakellariou, 2007), interpersonal attraction (Bekiari \& Spyropoulou, 2016; Syrmpas \& Bekiari, 2015), intrinsic motivation and lesson satisfaction (Bekiari, 2014; Bekiari, Perkos \& Gerodimos, 2015; Bekiari \& Syrmpas, 2015), discipline reasons (Bekiari, Kokaridas \& Sakellariou, 2006; Bekiari \& Tsiana, 2016). In sport settings verbally aggressive coaches are perceived as less favorable by their athletes and, simultaneously, are considered to present weaker sportsmanship. Nevertheless, trainees were less satisfied with their coaches and had lower win-loss percentages (Kassing \& Infante, 1999). Verbally aggressive coaches are regarded as less credible by their trainees and they possibly let them feel less motivated (Bekiari, Perkos \& Gerodimos, 2015; Mazer, Barnes, Grevious, \& Boger, 2013). Furthermore, the relationship between athletes' aggressiveness and the type of sport has been explored (Huang, Cherek \& Lane, 1999; Lemieux, McKelvie, \& Stout, 2002). Particularly, it has been suggested that athletes participating in non-contact sports regarded the coaches as less verbally aggressive in comparison with athletes who participate in high-contact sports (Bekiari, Digelidis \& 
Sakellariou, 2006). Additionally, male players of volleyball have considered anxiety to be higher and seemed to be more strongly affected by the coaches' verbal aggressiveness than female players (Bekiari, Patsiaouras, Kokaridas, \& Sakellariou, 2006).

\section{Leadership style}

The Multidimensional Model of Leadership proposed by Chelladurai (1978) consists of five instructors' leadership styles: the degree of democratic/ autocratic manner, the existence or not of training, the practicing or not of guidance, the implementation or not social support and the existence or not of positive feedback. A democratic coach allows participation of athletes in decision-making, while an autocratic one imposes his opinion. Practicing training and guidance characterizes coach focusing on sound preparation of athletes and on the need of positive feedback aiming at strengthening and encouragement of trainees. The socially supportive coach interacts effectively with athletes and concludes to interpersonal relationships (Chelladurai, 1978). Preferred leadership behaviors considered coaching and guidance, and the positive feedback and undesired leadership is autocratic (Surujlal, Dhurup, 2012). However, athletes are satisfied and the democratic style and social support (Moen, Hoigaard \& Peters, 2014). The socially supportive leadership style boosts morale and collective effectiveness of the group (Hampson \& Jowett, 2014), increases the enjoyment of athletes (Bray, Millen, Eidsness \& Leuzinger, 2005), satisfaction, motivation and desire to participate in physical activity (Chatzisarantis, \& Hagger, 2009). The positive feedback of the coaches enhances self- efficacy of athletes (Lloyd \& Little, 2010) and animation by coaches considered decisive for winning the race (Fransen, Vanbeselaere, De Cuyper, Broek \& Boen, 2014). The style of training and guidance is negatively related to the racing stress (Monemi \& Moghaddam, 2013), while the autocratic style is positively correlated with anxiety and the use of verbal aggressive behavior from the instructor (Bekiari, 2014).

\section{Motivational climate}

The concept of motivational climate derived from the AchievementGoal Theory (Ames \& Archer, 1988; Elliot \& Dweck, 1988; Nicholls, 1984). AGT proposes that people's behaviors which are leaded by goals are determined by the motivational environment in which they are exposed, as well as the orientation of their goals (Nicholls, 1989; Ames, 1992). Motivational climate has been defined as a moral environment that directs the goals of an action in achievement conditions (Ames, 1992; Ames \& Archer, 1988; Dweck \& Leggett, 1988; Jaakkola \& Digelidis, 2007; Nicholls, 1984; 1989). Two types of motivational climate have been proposed: the mastery- or task-oriented and the performance- or ego-oriented climate (Roberts, 
Treasure, \& Conroy, 2007). Certain behaviors and interactions are considered to contribute to the motivational climate, based on the effort to promote competition and being supportive, cooperative and affectionate (Vazou, Ntoumanis \& Duda, 2005; Keegan et al., 2009). Additionally, aspects about motivation are associated with perceptions of social interactions within the learning environment, such as perceptions of teacher's support (Patrick, Mantzicopoulos, Samarapungavan, \& French, 2008; Patrick, Ryan, \& Kaplan, 2007), classroom's climate (Dorman, 2001; Dorman \& Adams, 2004; Freeman, Anderman, \& Jensen, 2007; Kokaridas, Bekiari \& Sakellariou, 2005), school's climate (Anderman \& Anderman, 1999) and positive feelings about school (Witkow \& Fuligni, 2007). The motivational climate oriented to performance is promoted by the interpersonal competition, public valuation, and normative review. In contrast, mastery-oriented motivational climate is encouraged by the teacher's focus on education, self-improvement, tasks, such as optimally challenging work and effort (Ames, 1992). The climate that emphasizes social comparison and the results of performance, rather than the individual's learning process and improvement, can create feelings of anxiety and confusion (Liukkonen, Barkoukis, Watt \& Jaakkola, 2010). Studies reviewed by Braithwaite, Spray and Warburton (2011) showed adaptive outcomes (such as pleasure, loyalty and confidence) in students involved in mastery climate, while maladaptive effects (such as stress and boredom) resulted in performance climate. In sports motivational climate represents an achievement environment and its psychological structure, which can be enhanced by the coach, the team, their parents or a combination of all these (Barić \& Horga, 2007). Parents, peers and coaches contribute actively to the motivational climate faced by athletes (Le Bars, Gernigon, \& Ninot, 2009; O'Rourke, Smith, Smoll, \& Cummings, 2014). The mastery climate is positively associated with prosocial behavior, sportsperson ship, including respect for the game, the rules, officials, opponents and teammates and negatively associated with antisocial behavior. Conversely, a performance climate is positively associated with anti-social behavior and low levels of sportsperson ship and ethical function (Boardley \& Kavussanu, 2009; Kavussanu, 2006; Kavussanu \& Spray, 2006; Miller, Roberts, \& Ommundsen, 2004). A climate-oriented in performance typically is associated with tension, reduced positive attitudes toward the instructor, reduced performance and withdrawal of effort (Lau \& Nie, 2008; Nerstad et al., 2013a). Extensive research has shown that a task climate is likely to induce results such as prosperity, satisfaction, perseverance in work, achievement strategies in persistence and adaptability (Ntoumanis \& Biddle, 1999; Roberts, 2012). 


\section{Machiavellianism}

The Machiavellian person is characterized by the ability to influence other people and control them, and self-interest is the key motive of his behavior (Walter, Anderson, \& Martin, 2005). Machiavellian persons seem to be ideologically neutral, to present restricted emotional involvement in interpersonal relationships, and to avoid commitments when it is to their advantage to do so (Dahling, Whitaker, \& Levy, 2009; Mudrack \& Mason, 1995). It has been found that a significant negative relation appears between Machiavellianism and personality and conscientiousness (Paulhus \& Williams 2002). Simultaneously, a positive relation between Machiavellianism impatience and everesthisia (Aziz \& Vallejo, 2007). It has been shown that the characteristics of a non-genuine person are a good predictor of Machiavellianism (Ashton, Lee \& Son, 2000). A relationship appears also between moral judgments and Machiavellianism (McMahon \& Cohen, 2009; Mudrack, Bloodgood \& Turnley, 2012; Pan \& Sparks, 2012; Shafer \& Simmons, 2008). Dahling et al. (2009) identified four dimensions in Machiavellianism: distrust towards others, desire for power, desire for control and immoral manipulation. Machiavellian individuals seem also to use offensive and dishonest way to achieve their goal, manipulating and convincing others to perform, but they are not convinced by others (Christie $\&$ Geis, 1970). Moreover, these people tend to violate the rights of others in order to satisfy personal interest (Zagenczyk et al, 2014) and show deviant behavior. Finally, it has been argued that a positive relationship exists between aggression and Machiavellianism as the Machiavellian tactics connected both with abuse and aggressiveness in school context (Andreou, 2004), tending the Machiavellian students to be heartless, selfish and malicious in their interpersonal relations (Bereczkei, 2015).

\section{The present study}

Allowing for the above literature review, the present study aimed to investigate the relations among perceived instructors' verbal aggressiveness, leadership style and motivational climate and students' Machiavellianism in physical education classes. In particular, this study intends to answer the following research questions:

Are there any differences noted between the two sexes regarding verbal aggressiveness, leadership style, motivational climate and Machiavellianism?

- $\quad$ Is there a positive or negative relationship between instructors' verbal aggressiveness, their leadership style and motivational climate as perceived by students with students' self-reports of Machiavellianism in physical education classes? 
- $\quad$ To what extent the perceived instructors' verbal aggressiveness could be a significant predictor of their leadership style and motivational climate and the students' Machiavellianism?

Can students' and instructors' typology regarding parameters of verbal aggressiveness, leadership style, motivational climate perception and Machiavellianism be extracted?

In the light of the findings, useful conclusions is expected to be drawn regarding the relation of instructors' verbal aggressiveness, leadership style, motivational climate as perceived by students with students' self-reports of Machiavellianism in physical education classes.

\section{Method}

\section{Participants and Procedures}

The sample of the study consisted of 247 students (128 males, 119 females) aged 14-17 years old $(M=15.4, S D=.49)$. The sample was randomly selected from Thessaloniki region, Greece. All the participants were between the $2^{\text {nd }}, 3^{\text {st }}$, and $4^{\text {th }}$ grade of secondary schools and belonged to different socioeconomic status. All students completed questionnaires referring to the instructors' verbal aggressiveness, leadership style, motivational climate and students' Machiavellianism, during their physical education lessons. The questionnaires were fluently completed within 20-30 minutes. The anonymity of the informants was emphasized and the participation was voluntary. Thereby, sincere answers were expected. Best practice rules and research ethics were observed.

\section{Instruments}

Verbal aggressiveness. The Greek version (Bekiari \& Digelidis, 2015), which was used to assess physical education teacher verbal aggressiveness, relied on the theoretical framework and the Verbal Aggressiveness Questionnaire developed by Infante and Wigley (1986). Preliminary examination (Bekiari \& Digelidis, 2015) supported the psychometric properties of the instrument. In particular, confirmatory factor analysis indicated satisfactory fit indices (confirmatory factor analysis: .97, SRMR: .02), and internal consistency of the scale $(\alpha=.96)$. The scale consisted of eight items (e.g., 'the teacher insults students,' 'the teacher makes negative judgments of students' ability'). Participants were asked to respond on a 5-point Likert-type scale ranging from 1: Strongly disagree to 5: Strongly agree.

Leadership style. A shorter version of the Leadership Scale for Sports (L.S.S.), (Chelladurai \& Saleh, 1980), was used in order to measure perceived instructors' leadership style. This short version consisted of 6 items describing autocratic leadership (e.g., 'The instructor decides alone what to do regarding 
the organization and function of the school') and 5 items describing democratic leadership teaching style (e.g., 'The instructor allows students to set their own goals') only two of the five dimensions were used. Responses were given on a 5-point Likert-type scale ranging from 1: Strongly disagree to 5: Strongly agree.

Motivational climate. The motivational climate was measured with the short version of the Learning and Performance Orientations in Physical Education Classes Questionnaire (LAPOPEQ) (Papaioannou, 1998). The questionnaire consists of two scales referring to perceptions of instructorinitiated motivational climate. The first-seven-item scale measures perceptions of mastery climate (e.g., "The instructor is completely satisfied when every student's skills are improving") and the other six-item scale measures perceptions of the instructor's try to promote performance climate (e.g., "The instructor attends to the best records only"). CFA findings suggested that the overall two factors motivational climate model fit the data well (Hu \& Bentler, 1999): $(\mathrm{CMIN}=135.372$ [df $=54], \mathrm{CMIN} / \mathrm{df}=2.507$, TLI $=.966, \mathrm{CFI}=.976, \mathrm{RMSEA}=.064)$. The Cronbach's alpha value varied between .74 and .87 indicating good internal consistency for the scale. Based on both methods values (Spearman-Brown coefficient $=.85$ and Cronbach's $\alpha$ $=.90)$ it can be suggested that the reliability of the mastery climate is high. Following the item "In this training session," responses to the items were indicated on a five-point Likert-type scale (5=strongly agree, 1=strongly disagree).

Machiavellianism. A version of the Machiavellianism Scale (Mudrack \& Mason, 1995) was used in order to measure students' Machiavellianism. The Cronbach's alpha value was .87 indicating good internal consistency for the scale. The scale consisted of ten items (e.g., "Often behave with guile to achieve what you want?", "Do you like to manipulated people?", "Would you be willing to be ruthless to get ahead in your life?") and the students respond to a Likert five-point scale from "totally disagree" to "totally agree" (Totally disagree $=1$, Disagree $=2$, Somewhat agree $=3$, Agree $=4$ and Totally agree $=5$ ).

\section{Data analysis}

Data analysis included the use of the Statistical Package for Social Sciences (SPSS 21.0). Cronbach's $\alpha$ reliability analysis was used to examine the internal consistency of the factors of each questionnaire. The t-test for independent samples was used in order to reveal statistical significant differences between the two genders of the students. The Pearson correlation coefficient was used to measure the correlation between the subscales of the questionnaires. Moreover, regression analysis was conducted in order to explore the extent to which the perceived instructors' verbal aggressiveness could be a significant predictor of their leadership style and motivational 
climate and the students' Machiavellianism. The level of statistical significance was set at .05. Finally, students' and instructors' typology regarding parameters of verbal aggressiveness, leadership style, motivational climate perception and Machiavellianism will be formulated using principal component analysis.

\section{Results}

Cronbach's $\alpha$ reliability analysis for the 8-items verbal aggressiveness scale (Bekiari \& Digelidis, 2015) was .91. The factors of autocratic teaching style $(\alpha=.92)$ and democratic style $(\alpha=.93)$ of the questionnaire of Chelladurai and Saleh (1980) were high too. The factors of mastery climate $(\alpha=.89)$ and performance climate $(\alpha=.90)$ for the motivational climate scale (Papaioannou, 1998) showed a high degree of reliability. The factor of Machiavellianism scale (Mudrack \& Mason, 1995) showed a high level $(\alpha=.89)$ of reliability too.

Statistically significant differences were observed in instructors' verbal aggressiveness $\left(\mathrm{t}_{1,245}=3.50, \mathrm{p}<.05\right)$, autocratic leadership teaching style $\left(\mathrm{t}_{1,245}=3.18, \mathrm{p}<.05\right)$, democratic leadership style $\left(\mathrm{t}_{1,245}=-2.62, \mathrm{p}<.05\right)$ and Machiavellianism $\left(\mathrm{t}_{1,245}=3.61, \mathrm{p}<.05\right)$ between the two genders of the students (Table 1), while there were no differences between gender in mastery and performance motivational climate.

Table 1. Students' gender comparison

\begin{tabular}{cccccccc}
\hline Variables & Gender & $\mathrm{N}$ & Mean & $\mathrm{SD}$ & $\mathrm{t}$ & $\mathrm{df}$ & $\mathrm{p}$ \\
\hline Verbal aggressiveness & males & 128 & 3.58 & 1.09 & 3.50 & 245 & .001 \\
& females & 119 & 3.04 & 1.30 & & & \\
Autocratic style & males & 128 & 3.44 & 1.10 & 3.18 & 245 & .002 \\
& females & 119 & 2.96 & 1.23 & & & \\
Democratic style & males & 128 & 2.36 & 1.26 & - & 245 & .009 \\
& females & 119 & 2.82 & 1.46 & 2.62 & & \\
Machiavellianism & males & 128 & 3.20 & .79 & 3.61 & 245 & .000 \\
& females & 119 & 2.80 & .93 & & & \\
\hline
\end{tabular}

In addition, a correlation analysis was conducted, the results of which are presented in Table 2. As it can be seen, there was a negative significant relationship between instructors' verbal aggressiveness and democratic teaching style $(\mathrm{r}=-.82)$ and mastery climate $(\mathrm{r}=-.49)$. Also, there was a positive significant relationship between instructors' verbal aggressiveness and autocratic teaching style $(\mathrm{r}=.79)$, performance climate $(\mathrm{r}=.67)$ and Machiavellianism ( $\mathrm{r}=.91)$.

Table 2. Correlation analysis results

\begin{tabular}{ccccccc}
\hline & 1 & 2 & 3 & 4 & 5 & 6 \\
\hline 1.Verbal aggressiveness & 1.00 & & & & & \\
2. Autocratic style & $.79^{* *}$ & 1.00 & & & & \\
3. Democratic style & $-.82^{* *}$ & $-.78^{* *}$ & 1.00 & & & \\
4. Mastery climate & $-.49^{* *}$ & $-.46^{* *}$ & $.54^{* *}$ & 1.00 & & \\
\hline
\end{tabular}




\begin{tabular}{ccccccc}
\hline 5. Performance climate & $.67 * *$ & $.77 * *$ & $-.67 * *$ & $-.45^{* *}$ & 1.00 \\
6. Machiavellianism & $.91 * *$ & $.72 * *$ & $-.80^{* *}$ & $-.43^{* *}$ & $.63 * *$ & 1.00 \\
\hline \multicolumn{8}{c}{$* * \mathrm{p}<.001$} & & &
\end{tabular}

Moreover, a series of simple regression analyses were conducted to examine the extent to which leadership teaching style, motivational climate and Machiavellianism could be predicted from the ratings of instructor's verbal aggressiveness. The results indicated that perceived instructor verbal aggressiveness could predict significant variance in leadership teaching style $\left(\mathrm{F}_{(2,244)}=504.26, \mathrm{p}<.001\right)$ with an $\mathrm{R}_{2}$ of $79 \%$. Perceived verbal aggressiveness explained $2.5 \%$ of the variance in autocratic teaching style $\left(\beta=.28, \mathrm{t}_{(242)}=5.62\right.$, $\mathrm{p}<.001)$ and $14.7 \%$ of the variance in democratic teaching style $(\beta=-.59$, $\left.\mathrm{t}_{(242)}=-13.55, \mathrm{p}<.001\right)$. Another linear regression analysis was conducted to predict motivational climate based on instructor verbal aggressiveness. The results indicated that perceived instructor verbal aggressiveness could predict significant variance in motivational climate $\left(\mathrm{F}_{(2,244)}=148.60, \mathrm{p}<.001\right)$ with an $\mathrm{R}_{2}$ of $55 \%$. Verbal aggressiveness explained $3.7 \%$ of the variance in mastery motivational climate $\left(\beta=-.19, \mathrm{t}_{(242)}=-4.49, \mathrm{p}<.001\right)$ and $28.3 \%$ of the variance in performance motivational climate $\left(\beta=.59, \mathrm{t}_{(242)}=12.37, \mathrm{p}<.001\right)$. Finally, another linear regression analysis was conducted to predict students' Machiavellianism based on instructor verbal aggressiveness. The results indicated that perceived instructor verbal aggressiveness could predict significant variance in Machiavellianism $\left(\mathrm{F}_{(1,244)}=42.94 .19, \mathrm{p}<.001\right)$ with an $\mathrm{R}_{2}$ of $94 \%$. Verbal aggressiveness explained $93 \%$ of the variance in students' Machiavellianism $\left(\beta=1.36, \mathrm{t}_{(243)}=65.53, \mathrm{p}<.001\right)$. The results of the regression analyses are presented in Table 3.

Table 3. Regression analysis results according to verbal aggressiveness

\begin{tabular}{cccccc}
\hline & $\mathrm{B}$ & $95 \% \mathrm{CI} \mathrm{B}$ & $\mathrm{SE}$ & $\beta$ & $\mathrm{T}$ \\
\hline Autocratic style & .27 & $.18, .38$ & .05 & .28 & $5.60^{* *}$ \\
Democratic style & -.66 & $-.67,-.50$ & .04 & -.59 & $-.13 .55^{* *}$ \\
Mastery climate & -.19 & $-.28,-.11$ & .04 & -.22 & $-4.50^{* *}$ \\
Performance climate & .59 & $.50, .68$ & .05 & .61 & $12.37^{* *}$ \\
Machiavellianism & .95 & 1.29, & .02 & 1.35 & $65.51^{* *}$ \\
& & .1 .37 & & \\
\hline & $* * p<.001$ &
\end{tabular}

Moreover, in the Table 4, three types of relations between students and instructors may be distinguished: the "insurrection", the "acceptance of authoritarianism" and the "effective democracy". The first type is a generalized situation of oppression and Machiavellian reaction mostly emerging under the condition of emphasizing mastery-climate. The second type is a situation where even authoritarianism may be acceptable under conditions of no verbal aggressiveness. The third type seems to be a 
technocratic situation where performance-climate leaves scope of action or thinking.

Table 4. Mixed typology

\begin{tabular}{|c|c|c|c|}
\hline & "Insurrection" & $\begin{array}{c}\text { "Acceptance of } \\
\text { authoritarianism" }\end{array}$ & "Effective democracy" \\
\hline va1 & .946 & -.171 & .082 \\
\hline va2 & .882 & -.278 & .171 \\
\hline va3 & .838 & -.334 & .176 \\
\hline va4 & .934 & -.216 & .113 \\
\hline va5 & .922 & -.211 & .039 \\
\hline va6 & .920 & -.102 & -.060 \\
\hline va7 & .941 & -.176 & .018 \\
\hline va8 & .926 & -.031 & -.026 \\
\hline mach1 & .798 & -.038 & -.065 \\
\hline mach2 & .868 & -.150 & .010 \\
\hline mach3 & .870 & -.211 & .094 \\
\hline mach4 & .814 & -.195 & .046 \\
\hline mach5 & .797 & -.291 & .232 \\
\hline mach6 & .755 & -.378 & .118 \\
\hline mach7 & .859 & -.198 & .095 \\
\hline mach8 & .805 & -.288 & .161 \\
\hline mach9 & .519 & -.137 & .040 \\
\hline $\operatorname{mach} 10$ & .878 & -.160 & .075 \\
\hline mast1 & .891 & .234 & .051 \\
\hline perf2 & -.900 & -.038 & .321 \\
\hline mast3 & .850 & .408 & .184 \\
\hline perf4 & -.910 & -.042 & .323 \\
\hline mast5 & .851 & .381 & .184 \\
\hline perf6 & -.912 & -.039 & .292 \\
\hline mast7 & .902 & .222 & .090 \\
\hline perf8 & -.904 & -.040 & .307 \\
\hline mast 9 & .896 & .260 & .084 \\
\hline mast10 & .883 & .252 & .074 \\
\hline mast11 & .879 & .220 & .097 \\
\hline perf12 & -.904 & -.025 & .301 \\
\hline perf13 & -.912 & -.022 & .272 \\
\hline aut1 & .839 & .395 & .179 \\
\hline $\operatorname{dem} 2$ & -.915 & -.051 & .293 \\
\hline aut3 & .832 & .406 & .180 \\
\hline $\operatorname{dem} 4$ & -.904 & -.042 & .329 \\
\hline aut5 & .846 & .369 & .184 \\
\hline
\end{tabular}




\begin{tabular}{cccc} 
dem6 & $\mathbf{- . 9 0 7}$ & .005 & .272 \\
aut7 & $\mathbf{. 8 4 8}$ & $\mathbf{. 4 0 3}$ & .165 \\
dem8 & $\mathbf{- . 9 0 8}$ & -.042 & $\mathbf{. 3 1 3}$ \\
aut9 & $\mathbf{. 8 5 4}$ & $\mathbf{. 3 8 0}$ & .164 \\
dem10 & $\mathbf{- . 9 1 3}$ & -.039 & .287 \\
aut11 & $\mathbf{. 9 0 1}$ & .228 & .083 \\
\hline
\end{tabular}

Extraction Method: Principal Component Analysis

(va: verbal aggressiveness, mach: Machiavellianism, perf: performance, mast: mastery, aut: autocratic, dem: democratic)

\section{Discussion and challenges for future research}

The aim of this study was threefold: a) to explore the relationship between perceived instructor verbal aggressiveness, leadership style, motivational climate and student Machiavellianism, b) to investigate the influence of instructor verbal aggressiveness on their leadership style and motivational climate and student Machiavellianism in physical education context and c) to propose students' and instructors' typology. According to the results of the study, statistically significant differences were observed in instructors' verbal aggressiveness, autocratic leadership teaching style, democratic leadership style and students' Machiavellianism between the two genders of the students. Additionally, it was shown that perceived instructors' verbal aggressiveness was negatively related to their democratic teaching style and mastery climate. There was, also, a positive significant relationship between instructors' verbal aggressiveness and autocratic teaching style, performance climate and students' Machiavellianism. Moreover, it was revealed that perceived instructors' verbal aggressiveness could significantly predict the variables of leadership teaching style, motivational climate and students' Machiavellianism. Distinct types of relations between students and instructors may be distinguished: the "insurrection", the "acceptance of authoritarianism" and the "effective democracy".

Regarding differences concerning gender, it is here supported that male students perceived instructors as more verbally aggressive, more autocratic, more strongly susceptible to create performance-oriented climate and to present Machiavellian practices than female students in physical education context. This is in accordance with Infante (1989) who argued that educators are susceptible to be less verbally aggressive toward female. Usually, male appear to be less obedient toward instructors. This seems to increase the verbal aggressiveness of the instructors who, thereby, attempt to restore discipline. Similarly, the present study revealed that male students perceived the instructors as more verbally aggressive and more autocratic than female ones (Bekiari, 2014). In addition, male appear to be more familiar with physical violence or bulling episodes than female (Athanasiades \& DeliyanniKouimtzis, 2010). Weiss and Ferrer-Caja (2002) argue that male are expected 
to be more skillful and competitiveness than female according to social stereotypes.

In this study, the verbal aggressiveness of instructors proved to be positively related to the autocratic teaching style the Machiavellianism of the students. These findings seems to be indirectly in accordance with the tenor of previous research indicating that instructors' verbal aggressiveness was negatively related to students' intrinsic motivation, democratic teaching style, pro-social fair play behaviors, interpersonal attraction and satisfaction (Bekiari, 2012; 2014; Bekiari et al, 2015; Bekiari \& Syrmpas, 2015; Hamilton \& Hample, 2011; Hasanagas \& Bekiari, 2015; Hassandra, Bekiari \& Sakellariou, 2007; Myers, 2002; Myers \& Rocca, 2001; Syrmpas \& Bekiari, 2015; Theoharis \& Bekiari, 2016). Furthermore, it has been suggested that the personality of instructors strongly determines their relationship with the students and influences the latter's behavior, emotions, tactics and attitudes (Infante \& Rancer, 1996; Rancer \& Avtgis, 2014). This study, particularly, revealed that perceived instructor's verbal aggressiveness is a quite important predictor of students' Machiavellianism, which is in accordance with previous findings showing that instructors' verbal aggressiveness is negatively related to students' pro-social fair play behaviors (Hassandra, Bekiari \& Sakellariou, 2007), since Machiavellian persons using offensive and dishonest way to achieve their goal (Christie \& Geis, 1970), tend to present deviant behavior (Zagenczyk et al., 2014), using deception as a strategy to overturn the unjust and autocratic discipline (Talwar \& Lee, 2011). Furthermore, the Machiavellian adults show hostile feelings and hostile behavior (Locke \& Christiensen, 2007), as well as aggression (Andreou, 2004; Corzine \& Hozier, 2005), tending to be heartless, selfish and malicious in interpersonal relations (Bereczkei, 2015).

Also, in present study, there was a positive significant relationship between instructors' verbal aggressiveness and performance climate. These findings seem to be congruent with previous studies conducted in the education field. Particularly, previous findings supported that instructors' verbal aggressiveness is negatively related with students' motivation state (Myers, 2002; Myers \& Rocca, 2000; 2001). Such a motivation seems to be based on common background with intrinsic motivation which was in turn found to be positively related with mastery climate (Goudas, 1998). Presuming that competition is a dominant characteristic of physical education and instructors lay emphasis on personal performance by prioritizing achievement such as "who can score more points in basket ball", then instructors tend to adopt an aggressive behavior because of the tension enhanced by such a context. Nevertheless, in a physical education context in which learning is officially the prevalent goal, they would be expected to practice less verbally aggressive behavior. Thus, it is still questionable whether verbal 
aggressiveness is positively related with performance climate and negatively with mastery climate.

Moreover, three types of relations between students and instructors may be distinguished: the "insurrection", the "acceptance of authoritarianism" and the "effective democracy". The first type is a generalized situation of oppression and Machiavellian reaction mostly emerging under the condition of emphasizing mastery-climate. The second type is a situation where even authoritarianism may be acceptable under conditions of no verbal aggressiveness. The third type seems to be a technocratic situation where performance-climate leaves scope of action or thinking.

In case of "insurrection" a generalized oppression appears to take place due to the verbal aggressiveness and the authoritarianism attributed to the instructor. These conditions seem to cause dissatisfaction and, subsequently, a Machiavellian reaction in the part of the students. Additionally, the masteryclimate created by the instructors seems to be more demanding in dedication and adaptability of the way of thinking and learning behavior of the students, in contrast to a performance-climate which would demand only a superficial output from the students. This demand for a deeper mental dedication enhances the feeling of oppression and the Machiavellian reaction.

The "acceptance of authoritarianism" consists in a situation where an authoritarian instructor who demand from the students to adapt their way of thinking to his learning requests. He could be characterized a mentally totalitarian instructor who is, however, no verbally aggressive. The lack of verbal aggressiveness seems to convince the students that such a demanding instructor is characterized by self-confidence, that he regards the learning subject as an ideal and not just as a superficial objective (as the performance would be). In other word, he convinces with his behavior that he tries to serve his "ideal" and not to impose it or to promote his image or to emphasize his ego. Under these conditions, the students are more susceptible to believe that the instructor also believes in their mental qualifications and regards them as colleagues rather than as passive recipients of knowledge. Thus, a no verbally aggressive instructor, even if he is demanding in learning dedication of the students, he may appear as suggestive and convincing rather than as imposing.

The "effective democracy" challenges the classical assumption that effectiveness and legitimization are contracting values. In this case, the instructor who seeks a concrete goals related to performance seems to be more easily regarded as "democratic" than an instructor who demands total mental dedication to the learning patterns he imposes. The performance is a measurable objective. Thus, an instructor can simply say to the students: "achieve this, in the way you wish". If the students achieve the objective set, then both students and instructors will accept thus situation. Under this condition, the instructor abandons the role of a mental leader and behaves as 
a technocrat who assigns responsibilities to the students and confines his duty mainly on output-control (performance), leaving them to select the process ("how"). On the other hand, the learning is a subjective process implying understanding, adaptiveness of thinking and deeper mental dedication. This situation does not leave any scope of action and thinking. It is rather a mental dictatorship.

It can be concluded that physical education instructors' tendency to use negative communication techniques such as verbal aggressiveness, not only do not lead to mastery motivational climate but could additionally be harmful for their students (Martin et al. 2009). In future research, it could be examined which mechanisms formulating the relationship between instructors' verbal aggressiveness with students' intrinsic-extrinsic motivation, the Machiavellianism and bulling. Not only association but also causality between the variables can be explored. Thus, a longitudinal study could be a challenge for future research. Future studies could recruit larger number of students from other regions of Greece in order to increase findings' generalizability. A more balanced and comparative sampling e.g. between rural-urban interviewees can take place. Peer influence on motivational climate and students' satisfaction should be included in a future study.

\section{References:}

Ames, C. (1992). Classrooms: Goals, structures, and student motivation. Journal of Educational Psychology, 84(3), 261.

Ames, C., \& Archer, J. (1988). Achievement goals in the classroom: Students' learning strategies and motivation processes. Journal of Educational Psychology, 80(3), 260.

Anderman, L. H., \& Anderman, E. M. (1999). Social predictors of changes in students' achievement goal orientations. Contemporary Educational Psychology, 24(1), 21-37.

Andreou, E. (2004). Bully/victim problems and their association with Machiavellianism and self-efficacy in Greek primary school children. British Journal of Educational Psychology, 74(2), 297-309.

Ashton, M. C., Lee, K., \& Son, C. (2000). Honesty as the sixth factor of personality: Correlations with Machiavellianism, primary psychopathy, and social adroitness. European Journal of Personality, 14(4), 359-368.

Athanasiades, C., \& Deliyanni-Kouimtzis, V. (2010). The experience of bullying among secondary school students. Psychology in the Schools, 47(4), 328-341.

Aziz, A., \& Vallejo, D. (2007). An exploratory study of the facets of Type A personality and scores on the Machiavellian Behavior (MACH-B) Scale. Psychological reports, 101(2), 555-560. 
Barić, R., \& Horga, S. (2007). Psychometric properties of the croatian version of task and ego orientation in sport questionnaire (CTEOSQ). Kineziologija, 38(2), 135-142.

Bekiari, A. (2012). Perceptions of instructors' verbal aggressiveness and physical education students' affective learning. Perceptual and Motor Skills, $115,325-335$.

Bekiari, A. (2014). Verbal aggressiveness and leadership style of sport instructors and their relationship with athletes' intrinsic motivation. Creative Education, 5(2), 114-121.

Bekiari, A., \& Digelidis, N. (2015). Measuring verbal aggressiveness in sport and education. International Journal of Physical Education, 4, 12-21.

Bekiari, A., Digelidis, N., \& Sakelariou, K. (2006). Perceived verbal aggressiveness of coaches in volleyball and basketball: A preliminary study. Perceptual and Motor Skills, 103(2), 526-530.

Bekiari, A. \& Hasanagas, N. (2015). Sociological insights in the education system: "Unlocking” the power relations. Thessaloniki, Christodoulidis.

Bekiari, A. \& Hasanagas, N. (2015). Verbal Aggressiveness Exploration through Complete Social Network Analysis: Using Physical Education Students' Class as an Illustration. International Journal of Social Science Studies, 3(3), 30-49.

Bekiari, A., \& Hasanagas, N. (2016). Suggesting indicators of superficiality and purity in verbal aggressiveness. An application in adult education class networks of prisoners. Open Journal of Social Sciences, 4(3), 279-292.

Bekiari, A. \& Hasanagas, N. (2016). "Educating" in physical education. Theoretical approaches and practical inquiries. Thessaloniki, Christodoulidis.

Bekiari, A., Hasanagas, N., Theoharis, D., Kefalas, I. \& Vasilou, A. (2015). The role of mathematical object and the educational environment to students' interpersonal relationships: An application of full social network analysis. 32nd Congress Greek Mathematical Society, Kastoria 28/10-1/11/2015, pp. 799-812.

Bekiari, A., Kokaridas, D., \& Sakellariou, K. (2005). Verbal aggressiveness of physical education teachers and students' self-reports of behavior. Psychological Reports, 96, 493-498.

Bekiari, A., Kokaridas, D., \& Sakellariou, K. (2006). Associations of students' self-report of their teacher's verbal aggression, intrinsic motivation, and perceptions of reasons for discipline in Greek physical education classes. Psychological Reports, 98, 451-461.

Bekiari, A., \& Manoli, P. (2016). EFL teacher verbal aggressiveness and argumentativeness and student socio-affective strategy use and affective learning: Exploring possible associations. Journal of Teacher Education and Educators, 5(2) (forthcoming). 
Bekiari, A., Patsiaouras, A., Kokaridas, D., \& Sakellariou, K. (2006). The relationship between verbal aggressiveness and state anxiety in volleyball. Psychological Reports, 99(2), 630-634.

Bekiari, A., Perkos, S. \& Gerodimos, V. (2015). Verbal aggression in basketball: perceived coach use and athlete intrinsic and extrinsic motivation. Journal of Physical Education and Sport, 15(1), 96-102.

Bekiari, A. \& Sakellariou, K. (2002). Perceived instructor verbal aggressiveness and student state learning in physical education. Italian Journal of Sport Sciences, 1, 251-256.

Bekiari, A., \& Spyropoulou, S. (2016). Exploration of verbal aggressiveness and interpersonal attraction through social network analysis: Using university physical education class as an illustration. Open Journal of Social Sciences, 4, 145-155.

Bekiari, A. \& Syrmbas, I. (2015). The influence of motivational climate and coaches' verbal aggression on athletes' satisfaction. British Journal of Education, Society \& Behavioural Science, 9, 318-329.

Bekiari, A., \& Tsiana, I. (2016). Exploring instructors' verbal aggressiveness and students' personal orientations and reasons of discipline in physical education class. Advances in Physical Education, 6(3), 158-168.

Bereczkei, T. (2015). The manipulative skill: Cognitive devices and their neural correlates underlying Machiavellian's decision making. Brain and cognition, 99, 24-31.

Boardley, I. D., \& Kavussanu, M. (2009). The influence of social variables and moral disengagement on prosocial and antisocial behaviours in field hockey and netball. Journal of Sports Sciences, 27(8), 843-854.

Braithwaite, R., Spray, C. M., \& Warburton, V. E. (2011). Motivational climate interventions in physical education: A meta-analysis. Psychology of Sport and Exercise, 12(6), 628-638.

Bray, S. R., Millen, J. A., Eidsness, J., \& Leuzinger, C. (2005). The effects of leadership style and exercise program choreography on enjoyment and intentions to exercise. Psychology of Sport and Exercise, 6(4), 415-425.

Chatzisarantis, N. L., \& Hagger, M. S. (2009). Effects of an intervention based on self-determination theory on self-reported leisure-time physical activity participation. Psychology and Health, 24(1), 29-48.

Chelladurai, P. (1978). A contingency model of leadership in athletics (Doctoral dissertation, University of Waterloo).

Chelladurai, P., \& Saleh, S. D. (1980). Dimensions of leader behavior in sports: Development of a leadership scale. Journal of sport psychology, 2(1), 34-45.

Christie, R., \& Geis, F. L. (1970). Machiavellianism. Academic Press, Incorporated. 
Corzine, J. B., \& Hozier, G. C. (2005). Exploratory study of Machiavellianism and bases of social power in bankers. Psychological reports, 97(2), 356-362. Dahling, J., Whitaker, B., \& Levy, P. (2009). The Development and Validation of a New Machiavellianism Scale. Journal of Management, 35(2), 219-257. Dorman, J. P. (2001). Associations between classroom environment and academic efficacy. Learning Environments Research, 4(3), 243-257.

Dorman, J., \& Adams, J. (2004). Associations between students' perceptions of classroom environment and academic efficacy in Australian and British secondary schools. Westminster Studies in Education, 27(1), 69-85.

Dweck, C. S., \& Leggett, E. L. (1988). A social-cognitive approach to motivation and personality. Psychological Review, 95(2), 256.

Elliott, E. S., \& Dweck, C. S. (1988). Goals: an approach to motivation and achievement. Journal of Personality and Social Psychology, 54(1), 5.

Fransen, K., Vanbeselaere, N., De Cuyper, B., Vande Broek, G., \& Boen, F. (2014). The myth of the team captain as principal leader: extending the athlete leadership classification within sport teams. Journal of Sports Sciences, 32(14), 1389-1397.

Freeman, T. M., Anderman, L. H., \& Jensen, J. M. (2007). Sense of belonging in college freshmen at the classroom and campus levels. The Journal of Experimental Education, 75(3), 203-220.

Goudas, M. (1998). Motivational climate and intrinsic motivation of young basketball players. Perceptual and Motor Skills, 86(1), 323-327.

Jaakkola, T., \& Digelidis, N. (2007). Establishing a positive motivational climate in physical education. Psychology for Physical Educators: Student in Focus, 3-20.

Hamilton, M., \& Hample, D. (2011). Testing hierarchical models of argumentativeness and verbal aggressiveness. Communication Methods and Measures, 5(3), 250-273.

Hampson, R., \& Jowett, S. (2014). Effects of coach leadership and coachathlete relationship on collective efficacy. Scandinavian Journal of Medicine \& Science in Sports, 24(2), 454-460.

Hasanagas, N. \& Bekiari, A. (2015). Depicting determinants and effects of intimacy and verbal aggressiveness target through social network analysis. Sociology Mind, 5(3), 162-175.

Hassandra, M., Bekiari, A., \& Sakellariou, K. (2007). Physical education teacher's verbal aggression and student's fair play behaviors. The Physical Educator, 64(2), 94-101.

Hu, L. T., \& Bentler, P. M. (1999). Cutoff criteria for fit indexes in covariance structure analysis: Conventional criteria versus new alternatives. Structural equation modeling: a multidisciplinary journal, 6(1), 1-55. 
Huang, D. B., Cherek, D. R., \& Lane, S. D. (1999). Laboratory measurement of aggression in high school age athletes: Provocation in a nonsporting context. Psychological Reports, 85(3), 1251-1262.

Infante, D. A. (1989). Response to high argumentatives: Message and sex differences. Southern Communication Journal, 54(2), 159-170.

Infante, D. A., \& Rancer, A. S. (1996). Argumentativeness and verbal aggressiveness: A review of recent theory and research. In B.R. Burleson (Ed.) Communication yearbook, 19 (pp.319-351). Beverly Hills, CA: Sage.

Infante, D.A., \& Wigley, C.J. (1986) Verbal aggressiveness: an interpersonal model and measure. Communication Monographs, 53, 61-69.

Kassing, J. W., \& Infante, D. A. (1999). Aggressive communication in the coach-athlete relationship. Communication Research Reports, 16(2), 110-120. Kavussanu, M. (2006). Motivational predictors of prosocial and antisocial behaviour in football. Journal of Sports Sciences, 24(6), 575-588.

Kavussanu, M., \& Spray, C. M. (2006). Contextual influences on moral functioning of male youth footballers. The Sport Psychologist, 20(1), 1-23.

Keegan, R. J., Harwood, C. G., Spray, C. M., \& Lavallee, D. E. (2009). A qualitative investigation exploring the motivational climate in early career sports participants: Coach, parent and peer influences on sport motivation. Psychology of sport and exercise, 10(3), 361-372.

Kokaridas, D., Bekiari, A., Sakellariou, K. (2005). Students' goal orientations, perceived motivation climate and their relation with the selection of a specialty. Journal of Human Movement Studies, 48, 181-194.

Lau, S., \& Nie, Y. (2008). Interplay between personal goals and classroom goal structures in predicting student outcomes: A multilevel analysis of person-context interactions. Journal of educational Psychology, 100(1), 15.

Le Bars, H., Gernigon, C., \& Ninot, G. (2009). Personal and contextual determinants of elite young athletes' persistence or dropping out over time. Scandinavian Journal of Medicine \& Science in Sports, 19(2), 274-285.

Lemieux, P., McKelvie, S. J., \& Stout, D. (2002). Self-reported hostile aggression in contact athletes, no contact athletes and non-athletes. Athletic Insight, 4(3).

Liukkonen, J., Barkoukis, V., Watt, A., \& Jaakkola, T. (2010). Motivational climate and students' emotional experiences and effort in physical education. The Journal of Educational Research, 103(5), 295-308.

Locke, K. D., \& Christensen, L. (2007). Re-construing the relationalinterdependent self-construal and its relationship with self-consistency. Journal of Research in Personality, 41(2), 389-402.

Manoli, P., Bekiari, A. (2015). EFL teachers' verbal aggressiveness and students' intrinsic motivation and social-affective strategy use: investigating possible relations. Advances in Research, 5(6), 1-13. 
Martin, M. M., Rocca, K. A., Cayanus, J. L., \& Weber, K. (2009). Relationship between coaches' use of behavor alteration techniques and verbal aggression on athletes' motivation and affect. Journal of Sport Behavior, 32(2), 227.

Mazer, J. P., Barnes, K., Grevious, A., \& Boger, C. (2013). Coach verbal aggression: A case study examining effects on athlete motivation and perceptions of coach credibility. International Journal of Sport Communication, 6(2), 203-213.

McMahon, J. M., \& Cohen, R. (2009). Lost in cyberspace: ethical decision making in the online environment. Ethics and Information technology, 11(1), $1-17$.

Miller, B. W., Roberts, G. C., \& Ommundsen, Y. (2004). Effect of motivational climate on sportspersonship among competitive youth male and female football players. Scandinavian Journal of Medicine \& Science in Sports, 14(3), 193-202.

Moen, F., Høigaard, R., \& Peters, D. M. (2014). Performance progress and leadership behavior. International Journal of Coaching Science, 8(1), 69-81. Monemi, S.T. \& Moghaddam, A. (2013).The relationship between leadership style and competitive anxiety of female athletes. International Journal of Sport Studies, 3(12), 1387- 1392.

Mudrack, P. E., Bloodgood, J. M., \& Turnley, W. H. (2012). Some ethical implications of individual competitiveness. Journal of Business Ethics, 108(3), 347-359.

Mudrack, P. E., \& Mason, E. S. (1995). More on the acceptability of workplace behaviors of a dubious ethical nature. Psychological Reports, 76(2), 639-648.

Myers, S. A. (2002). Perceived aggressive instructor communication and student state motivation, learning, and satisfaction. Communication Reports, 15, 113-121.

Myers, S. A., Edwards, C., Wahl, S. T., \& Martin, M. M. (2007). The relationship between perceived instructor aggressive communication and college student involvement. Communication Education, 56(4), 495-508.

Myers, S. A., Brann, M., \& Martin, M. M. (2013). Identifying the content and topics of instructor use of verbally aggressive messages. Communication Research Reports, 30(3), 252-258.

Myers S. A., \& Rocca K.A. (2000). The relationship between perceived Instructor Communicator style argumentativeness, and verbal aggressiveness. Communication Research Reports, 17, 1-12.

Myers, S. A., \& Rocca, K. A. (2001). Perceived instructor argumentativeness and verbal aggressiveness in the college classroom: Effects on student perceptions of climate, apprehension, and state motivation. Western Journal of Communication (includes Communication Reports), 65(2), 113-137. 
Nerstad, C. G., Roberts, G. C., \& Richardsen, A. M. (2013). Achieving success at work: Development and validation of the Motivational Climate at Work Questionnaire (MCWQ). Journal of Applied Social Psychology, 43(11), 22312250.

Nicholls, J. G. (1984). Achievement motivation: Conceptions of ability, subjective experience, task choice, and performance. Psychological Review, 91(3), 328.

Nicholls, J. G. (1989). The competitive ethos and democratic education. Harvard University Press.

Ntoumanis, N., \& Biddle, S. J. (1999). A review of motivational climate in physical activity. Journal of sports sciences, 17(8), 643-665.

O'Rourke, D. J., Smith, R. E., Smoll, F. L., \& Cumming, S. P. (2014). Relations of parent-and coach-initiated motivational climates to young athletes' self-esteem, performance anxiety, and autonomous motivation: who is more influential? Journal of Applied Sport Psychology, 26(4), 395-408.

Pan, Y., \& Sparks, J. R. (2012). Predictors, consequence, and measurement of ethical judgments: Review and meta-analysis. Journal of business research, 65(1), 84-91.

Papaioannou, A. (1998). Students' perceptions of the physical education class environment for boys and girls and the perceived motivational climate. Research Quarterly for Exercise and Sport, 69(3), 267-275.

Patrick, H., Mantzicopoulos, P., Samarapungavan, A., \& French, B. F. (2008). Patterns of young children's motivation for science and teacher-child relationships. The Journal of Experimental Education, 76(2), 121-144.

Patrick, H., Ryan, A. M., \& Kaplan, A. (2007). Early adolescents' perceptions of the classroom social environment, motivational beliefs, and engagement. Journal of Educational Psychology, 99(1), 83.

Paulhus, D. L., \& Williams, K. M. (2002). The dark triad of personality: Narcissism, Machiavellianism, and psychopathy. Journal of research in personality, 36(6), 556-563.

Rancer, A. S., \& Avtgis, T. A. (2014). Argumentative and aggressive communication, 2d ed. New York: Peter Lang.

Roberts, G. C. (2012). Motivation in sport and exercise from an achievement goal theory perspective: After 30 years, where are we. Advances in motivation in sport and exercise, 3, 5-58.

Roberts, G. C., Treasure, D. C., \& Conroy, D. E. (2007). Understanding the dynamics of motivation in sport and physical activity: An achievement goal interpretation. Handbook of Sport Psychology, Third Edition, 1-30.

Rocca, K. A., \& McCroskey, J. C. (1999). The interrelationship of student ratings of instructors' immediacy, verbal aggressiveness, homophily, and interpersonal attraction. Communication education, 48(4), 308-316. 
Samar, R. G., \& Amiri, M. (2012). Aggression and Oral proficiency: A Correlational Study. Iranian Journal of Applied Linguistics, 1, 69-95.

Shafer, W. E., \& Simmons, R. S. (2008). Social responsibility, Machiavellianism and tax avoidance: A study of Hong Kong tax professionals. Accounting, Auditing \& Accountability Journal, 21(5), 695-720.

Surujlal, J., \& Dhurup, M. (2012). Athlete preference of coach's leadership style. African Journal for Physical, Health Education, Recreation \& Dance, 18(1).

Syrmpas, I, Bekiari, A. (2015). The Relationship between Perceived Physical Education Teacher's Verbal Aggressiveness and Argumentativeness with Students' Interpersonal Attraction. Inquiries in Sport \& Physical Education, 13(2), 21-32.

Talwar, V., \& Lee, K. (2011). A punitive environment fosters children's dishonesty: A natural experiment. Child development, 82(6), 1751-1758.

Teven, J. J. (2007). Teacher temperament: Correlates with teacher caring, burnout, and organizational outcomes. Communication Education, 56(3), 382400 .

Teven, J. J., \& McCroskey, J. C. (1997). The relationship of perceived teacher caring with student learning and teacher evaluation. Communication Education, 46(1), 1-9.

Theoharis, D. \& Bekiari, A. (2016). The influence of mathematics and learning environment in verbal aggressiveness and interpersonal relations: A dynamic analysis of social networks. $8^{\text {th }}$ International Congress Mathematical Society, Thessaloniki 30/3-3/4/2016 (Full Paper).

Thweatt, K. S., \& McCroskey, J. C. (1998). The impact of teacher immediacy and misbehaviors on teacher credibility. Communication Education, 47(4), 348-358.

Vazou, S., Ntoumanis, N., \& Duda, J. L. (2005). Peer motivational climate in youth sport: A qualitative inquiry. Psychology of Sport and Exercise, 6(5), 497-516.

Walter, H. L., Anderson, C. M., \& Martin, M. M. (2005). How subordinates' Machiavellianism and motives relate to satisfaction with superiors. Communication Quarterly, 53(1), 57-70.

Weiss, M. \& Ferrer-Caja (2002). Motivational orientations and sport behavior. Advances in sport psychology, 5, 101-171.

Witkow, M. R., \& Fuligni, A. J. (2007). Achievement goals and daily school experiences among adolescents with Asian, Latino, and European American backgrounds. Journal of Educational Psychology, 99(3), 584.

Zagenczyk, T. J., Restubog, S. L. D., Kiewitz, C., Kiazad, K., \& Tang, R. L. (2014). Psychological contracts as a mediator between Machiavellianism and employee citizenship and deviant behaviors. Journal of Management, 40(4), 1098-1122. 